TAPROBANICA, ISSN 1800-427X. November, 2020. Vol. 09, No. 02: pp. 164-173, pl. 49-50. (C) Research Center for Climate Change and Department of Biology, Faculty of Mathematics \& Natural Sciences, University of Indonesia, Depok 16424, INDONESIA. http://www.taprobanica.org/ https://doi.org/10.47605/tapro.v9i2.229

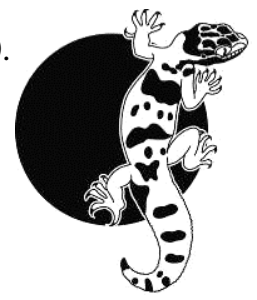

\title{
A NEW CRYPTIC SPECIES OF BUSH FROG (AMPHIBIA: ANURA: Raorchestes) FROM THE SOUTHERN EASTERN GHATS, INDIA
}

\author{
Gaurang G. Gowande ${ }^{1,2}$, S.R. Ganesh ${ }^{3}$ \& Zeeshan A. Mirza ${ }^{4}$ \\ ${ }^{1}$ Department of Biodiversity, Abasaheb Garware College, Pune 411004, Maharashtra, India \\ ${ }^{2}$ Department of Biotechnology, Fergusson College, Pune 41 1004, Maharashtra, India \\ ${ }^{3}$ Chennai Snake Park, Guindy, Chennai 600022, Tamil Nadu, India \\ ${ }^{4}$ National Centre for Biological Sciences, TIFR, Bengaluru 560065, Karnataka, India \\ ${ }^{4}$ Corresponding author. E-mail: snakeszeeshan@gmail.com
}

\begin{abstract}
A new cryptic lineage of bush frogs of the genus Raorchestes from the understudied Eastern Ghats of India is described. Molecular phylogenetic reconstructions using mitochondrial 16S rRNA gene sequences suggest that the new species belongs to the Raorchestes charius clade, is sister to the allopatric $R$. charius of the Western Ghats and support the species-level distinctiveness of the lineage. The new species morphologically resembles $R$. charius from which it can be distinguished using the following characters: narrower head (HW/SVL 0.31 vs $0.34-0.36$ ), wider inter upper eyelid (IUE/SVL 0.14-0.16 vs 0.11-0.13), greater maximum upper eyelid width (UEW/SVL 0.10-0.12 vs 0.06-0.09) and shorter thigh (TL/SVL 0.32-0.43 vs 0.44-0.51). Acoustic observations from the breeding males further corroborate the distinct specific status of the new species. The discovery of this new species of bush frog from an understudied landscape suggests that additional extensive surveys in the Eastern Ghats would yield several more amphibian lineages yet unknown to science.
\end{abstract}

Key words: arboreal frog, cryptic species, Kollimalai Massif, Philautus, Rhachophoridae, systematics

\section{Introduction}

Bush Frogs, genus Raorchestes Biju, Shouche, Dubois et al., 2010, belong to the arboreal frog family Rhachophoridae. These frogs were earlier placed in the genus Philautus Gistel, 1848, however molecular phylogenetic reconstruction revealed the polyphyly in the genus (Biju et al. 2010, Vijayakumar et al. 2014). The Peninsular Indian and Sri Lankan representatives were consequently shifted to the genera Raorchestes and Pseudophilautus Laurent, 1943 (Biju et al.
2010). Currently, more than 50 species of Raorchestes are known from India, primarily from the Western Ghats and north-east India. On the other hand, bush frogs of the drier Eastern Ghats have received comparatively little taxonomic attention. About five species of bush frogs were previously described from the Eastern Ghats: Philautus sanctisilvaticus Das \& Chanda, 1998; P. terebrans Das \& Chanda, 1998; P. similipalensis Dutta, 2003; $R$. cf. leucolatus Vijaykumar, Dinesh, Prabhu et al., 
2014 (Ganesh \& Arumugam 2016) and Pseudophilautus cf. wynaadensis (Jerdon, 1853). However, Mirza et al. (2019) showed that the first three species also belong to the genus Raorchestes and represent not three, but a single species, $R$. sanctisilvaticus. The taxonomic status of the population inhabiting the Kolli Hills of $R$. cf. leucolatus and $P$. cf. wynaadensis in the Eastern Ghats remains unstudied. During a recent survey of the herpetofauna in the Kollimalai Massif, southern Eastern Ghats, we encountered and collected bush frog specimens of the genus Raorchestes. We tentatively identified the specimens as $R$. charius, due to the overall morphological similarity. Ganesh \& Arumugam (2016) identified this population as Raorchestes cf. leucolatus. However, detailed morphological, molecular and acoustic analyses revealed that these specimens represent an undescribed, cryptic species of the $R$. charius clade. Here we describe and present a detailed morphological, molecular and acoustic account to diagnose the new species and distinguish it from its congeners.

\section{Material and Methods}

Fieldwork and specimen acquisition: One of us (SRG) undertook fieldwork throughout the Kolli Hills during 2011-2012 and observations on this species from those surveys are summarized in Ganesh \& Arumugam (2016). However, no specimens were collected during this period. In October 2018, GG \& ZM conducted a short survey during which Raorchestes sp. specimens were located in the field by the calls of the males at night. Specimens were collected by hand and subsequently euthanized with Tricaine Methanesulfonate (MS 222) following standard euthanasia protocols for amphibians. Thigh muscle tissue was collected and preserved in $>95 \%$ ethanol for DNA extraction purposes. The specimens were subsequently fixed in $4 \%$ formaldehyde buffer for 24 hours, after which they were washed in water for five hours and transferred to $70 \%$ ethanol solution for longterm preservation. Photographs were taken in preservative $(70 \%$ ethanol) with a Canon $70 \mathrm{D}$ illuminated with a Canon MT-24EX flash.

The specimens have been deposited at the Bombay Natural History Society, Mumbai (BNHS) and the collection facility of the National Centre for Biological Sciences, Bangalore (NCBS). Comparison of the new species was largely based on the topotypes of $R$. charius BNHS 4420 and BNHS 4421, two adult males, from Chikmagalur, Karnataka.

Acoustic data and analysis: Calls of a breeding male were recorded in the field using the voice recorders loaded on an android mobile phone, and were analyzed later using RavenPro v1.5. Range, mean and standard deviation were calculated from five individual notes of a call. Calls were compared with the calls of breeding males of other species that showed genetic affinity. Published acoustic data of $R$. charius were used to make these comparisons (Priti et al. 2016).

Molecular analysis: Complete genomic DNA was isolated from the preserved tissues using Qiagen DNAeasy kits following protocols directed by the manufacturer. A fragment of the mitochondrial 16S rRNA gene was amplified using the primers 16SarL and 16Sbr (Yu et al. 2009). A $12 \mu \mathrm{l}$ reaction was set containing $5 \mu \mathrm{l}$ of QiagenTaq PCR Master Mix, $4 \mu 1$ of water, $0.5 \mu 1$ of each primer and $2 \mu 1$ template DNA, carried out with an Eppendorf Mastercycler Nexus GSX1. Thermo-cycle profile used for amplification were as follows: $94^{\circ} \mathrm{C}$ for 15 minutes, (denaturation temperature $94^{\circ} \mathrm{C}$ for 50 seconds, annealing temperature $45^{\circ} \mathrm{C}$ for 50 seconds, elongation temperature $72^{\circ} \mathrm{C}$ for 2 minutes) x 30 cycles, $72^{\circ} \mathrm{C}$ for 15 minutes, hold at $4^{\circ} \mathrm{C}$. PCR product was cleaned using QIAquick PCR Purification Kit and sequenced with an AB 3730 DNA Analyzer. Sequences for 16s rRNA gene of selected bush frog species were downloaded following (Vijayakumar et al. 2016). Downloaded sequences were aligned in MegaX (Kumar et al. 2018) using ClustalW (Thompson et al. 2003) with default settings. Maximum Likelihood method for describing the phylogeny was implemented using W-IQ-TREE (Trifinopoulus et al. 2016), the web implementation of IQ-TREE (Nguyen et al. 2015). Branch support was tested using ultrafast bootstrap (UFboot) analysis (Minh et al. 2013), performing 1000 bootstrap alignments. TIM2e+I model of sequence evolution was used for ML analysis, which was selected following the model test run using ModelFinder (Kalyaanamoorthy et al. 2017). For optimal partitioning strategy and evolutionary substitution model for BI analysis, aligned data were analyzed using PartitionFinder v.1.1.1. (Lanfear et al. 2012). Bayesian Inference (Appendix III) was implemented in MyBayes 3.2.2 (Ronquist \& Huelsenbeck 2003) and was run for 10 million generations and sampled every 1000 generations, under GTR model of 
sequence evolution. BI run included five parallel chains, three hot and tow cold chains. The standard deviation of split frequencies of the analysis reached were below 0.01 , and the analysis was not continued further. Twenty-five percent of trees generated were discarded as burn-in. Un-corrected p-distance (divergence) was calculated in MegaX and a pairwise deletion was adopted to deal with missing data and gaps. Data for NADH dehydrogenase 1 (NDI) generated by Vijaykumar et al. (2014) and pdistance for the same is also presented (Table 1).

Morphological analysis: The new species was compared with other members of the $R$. charius clade using morphometric data from Biju \& Bossuyt (2009) and Bossuyt \& Dubois (2001) for $R$. charius, and from Priti et al. (2016) for $R$. honnametti Gururaja, Priti, Roshmi et al., 2016.

The following morphometric data were collected using digital calipers, to the nearest $0.01 \mathrm{~mm}$ : snout-vent length (SVL), head width (HW), head length (HL), inner upper eyelid width (IUE), maximum upper eyelid width (UEW), snout length (SL), eye length (EL), internarial distance (IN), nostril-snout distance (NS), eye-nostril distance (EN), tympanum-eye distance (TYE), distance from rear of the mandible to the nostril (MN), distance from rear of the mandible to the anterior orbital border of the eye (MFE), distance from rear of the mandible to the posterior orbital border of the eye (MBE), distance between the anterior corner of the eyes (IFE), distance between the posterior corner of the eyes (IBE), largest tympanum diameter (TYD), forelimb length (FLL), hand length (HAL), thigh length (TL), shank length (ShL), foot length (FOL), distance from the heel to the tip of the fourth toe (TFOL), disc width on fingers I, II, III, IV (FD I, II, III, IV), width of fingers I, II, III, IV (FW I, II, III, IV), length of fingers I, II, III, IV (FL I, II, III, IV), tibia width (TW), disc width on toes I, II, III, IV (TD I, II, III, IV), width of toes I, II, III, IV (TW I, II, III, IV), length of inner metatarsal tubercle (IMT), distance from distal edge of metatarsal tubercle to maximum incurvature of web between fourth and fifth toe (MTFF).

A total of 31 characters for all the specimens were recorded. Measurements and acronyms follow Gururaja et al. (2007), Biju \& Bossuyt (2009) and Priti et al. (2016). In the morphological comparisons section, the values in parenthesis follow (new species $v s$ compared species) format.

\section{Results}

Molecular phylogenetic reconstruction based on the $\sim 515 \mathrm{bp}$ long fragment of 16S rRNA mitochondrial gene (Fig. 1) suggests that the new species belongs to the $R$. charius clade (Vijayakumar et al. 2014, Priti et al. 2016) and is a sister to $R$. charius with high support (ML 100, BI 1.0). The clade containing the new species and $R$. charius is a sister to $R$. honnametti with high support (ML 100, BI 1.0). The intra-specific genetic p-distance is $0-0.02 \%$ $(n=4)$, whereas the species is $1.2-1.9 \%$ divergent from $R$. charius; for $580 \mathrm{bp}$ of mitochondrial NDl the new species shows a divergence of $5 \%$ from $R$. charius (Tables 1,2). The interspecific p-distance obtained between the new species and $R$. charius is reasonably shallow for its recognition as a distinct species. Nonetheless, morphology and acoustics, in addition with geography, establish its distinctness, which is here described as a cryptic species of the $R$. charius clade. A sequence from unknown locality generated by Vijayakumar et al. (2014), labelled as an unidentified species of bush frogs was found to be conspecific with the new species. This sequence was recovered as a member of the $R$. charius clade, sister to $R$. charius by Vijayakumar et al. $(2014,2016)$.

\section{Systematics}

The new species is identical in general appearance to $R$. charius. However, it can be distinguished from the latter by a few morphometric variables, by its call and and by its allopatric distribution in lowland dry forest. The combination of low genetic as well as morphological divergence hints at a recent diversification, a case common with most cryptic species.

Table 1. Un-corrected p-distance calculated for the mitochondrial NDl gene for Raorchestes species.

\begin{tabular}{lcccccc}
\hline $\begin{array}{l}\text { Genbank AN \& } \\
\text { Species }\end{array}$ & 1 & 2 & 3 & 4 & 5 & 6 \\
\hline $\begin{array}{l}\text { EU450060 } \\
\text { R. marki }\end{array}$ & & & & & & \\
$\begin{array}{l}\text { EU450043 } \\
\text { R. charius }\end{array}$ & 0.21 & & & & & \\
JX092870 & 0.21 & 0.00 & & & & \\
$\begin{array}{l}R . \text { charius } \\
\text { EU450033 }\end{array}$ & 0.19 & 0.14 & 0.14 & & & \\
$\begin{array}{l}\text { R. griet } \\
\text { EU450035 }\end{array}$ & 0.20 & 0.19 & 0.19 & 0.15 & & \\
$\begin{array}{l}R . \text { coonoorensis } \\
\text { JX092910 }\end{array}$ & 0.20 & 0.19 & 0.19 & 0.15 & 0.13 & \\
$\begin{array}{l}R . \text { aff. coonoorensis } \\
\text { JX092893 }\end{array}$ & 0.19 & 0.05 & 0.05 & 0.13 & 0.17 & 0.18 \\
$R$. kollimalai sp.nov. & & & & & & \\
\hline
\end{tabular}




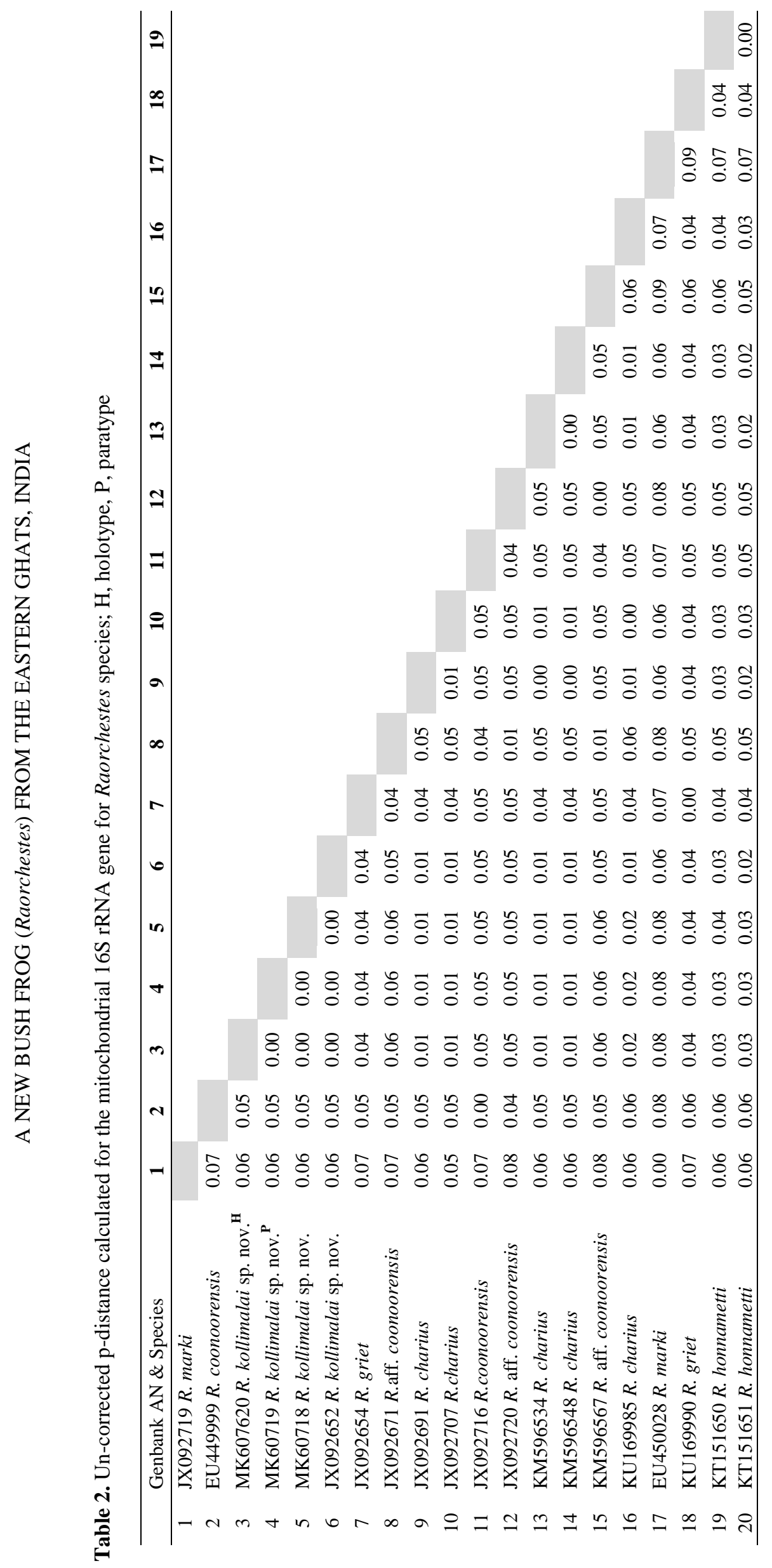




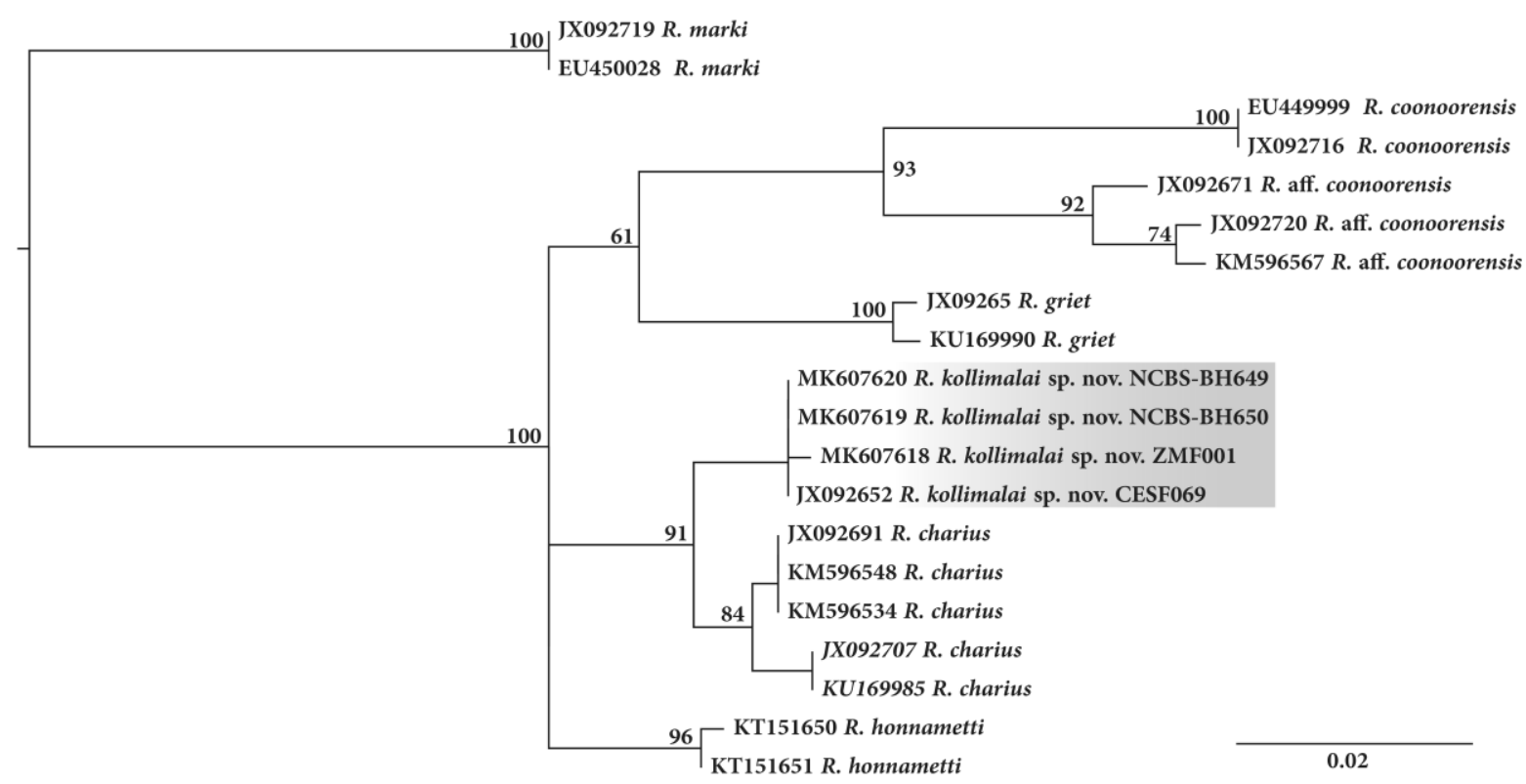

Figure 1. Maximum likelihood phylogeny of the members of the "Raorchestes charius" clade based on 16s rRNA gene reconstructed through 1000 non-parametric bootstrap replicates. Numbers at nodes represent bootstrap support

Raorchestes kollimalai sp. nov. [urn:lsid:zoobank.org:act:BDC8951D-62DA-44CAA67E-531E098FA78C]

(Figs. 1-5, Tables 3, 4)

Raorchestes cf. leucolatus — Ganesh \& Arumugam 2016: 10

Holotype. Adult male, NCBS-BH649, collected from low-lying shrubs at Kollimalai Massif $\left(11.245840{ }^{\circ} \mathrm{N}, 78.335365{ }^{\circ} \mathrm{E}\right.$; alt. $1,100 \mathrm{~m}$ a.s.1.), Namakkal District, Tamil Nadu, India, by A. Gawai, P. Phansalkar, G. Gowande, and Z. Mirza on $26^{\text {th }}$ October 2018 at 22:00 h.

Paratypes $(\boldsymbol{n}=2)$. Males, NCBS-BH650 and BNHS 6068, collection details same as the holotype.

Diagnosis. Raorchestes kollimalai sp. nov. is allocated to the genus Raorchestes based on the following combination of diagnostic characters: relatively small adult body size (SVL 15-45 $\mathrm{mm}$ ), absence of vomerine teeth, presence of vocal sacs, which appear transparent/translucent while calling, and nocturnal habits. Dorsum light brown with dark brown spots. Canthus rostralis dark brown, a dark brown streak from posterior of the eye through the tympanic region terminating at the shoulder. Legs banded with dark brown. Pupil black with gold specks around it. A medium-sized bush frog (SVL 25.8-29.7 $\mathrm{mm}, n=3$ ), characterized by wider than long head (HW/SVL 0.31, HL/SVL 0.26-0.30), short or subequal snout in comparison to the eye
(SL/SVL 0.12-0.14 vs EL/SVL 0.14-0.15) and by relatively shorter hind limbs (ShL/SVL<0.50).

Description of holotype. A male (NCBSBH649), medium-sized (SVL $29.6 \mathrm{~mm}$ ). Head slightly wider than long (HW 9.4, HL 9.1); snout rounded in dorsal and ventral view, as long as the eye (SL 4.2, EL 4.2, MFE 5.7, MBE 1.7), shorter than the distance from the rear of the mandible to the nostril (MN 7.8); canthus rostralis rounded; distance between the posterior corner of the eye 1.8 times greater than the distance between the anterior corner of the eye (IBE 8.2, IFE 4.6); tympanum indistinct (TYD 1.2), supratympanic fold distinct, from the posterior border of the eye to the shoulder; nostril distinct, rounded; loreal region slightly concave. Nostrils without flap, closer to the tip of the snout (NS 1.5, EN 1.9). Eye large (EL 4.2), protruding, pupil horizontal. Interorbital region flat, distance between the upper eyelids (IUE 4.7) greater than the maximum upper eyelid width (UEW 3.2) and the internarial distance (IN 2.7). Symphyseal knob not protruding the maxilla, pineal ocellus absent. Tongue bifurcated, smooth lacking lingual papilla. Forelimb nearly as long as the hand (FLL $8.2 v s$ HAL 8.1), $3^{\text {rd }}$ finger longest (FL III $5.1), 1^{\text {st }}$ shortest (FL I 2.6), relative length of the fingers: III (5.1) > IV (3.9) > II (3.2) > I (2.6), all fingers with very well-developed discs (FD I $=0.8, \mathrm{FD}$ II $=1.2, \mathrm{FD}$ III $=1.5, \mathrm{FD} \mathrm{IV}=1.4)$; 
discs wider than the fingers (FD III $1.5 v s$ FW III 1.0) with circum-marginal grooves, intercalary ossification present between penultimate and distal phalanges. Dermal fringe present only on the outer aspect of hind-limb. Hindlimbs short, do not touch or overlap when folded at right angles to the body, shank more than 5 times longer than wide (ShL $13.2 v s$ TW 2.6), longer than thigh (TL 10.3) and the foot (FOL 11.6), the foot being longer than the distance from the heel to the tip of the fourth toe (TFOL 10.9). Relative toe lengths IV $>$ III $>$ V $>$ II $>$ I $($ ToL $\mathrm{I}=2.6$, ToL $\mathrm{II}=2.9$, ToL $\mathrm{III}=4.8$, ToL IV= 6.9, ToL V= 4.6). Toe with well-developed discs at its distal tip (TD I= 0.7 , TD II $=0.9$, TD III= 1, TD IV= 1.3, TD V= 1.4, ); (TW I= 0.6, TW II $=0.5$, TW III=0.7, TW $\mathrm{IV}=0.9$, TW $\mathrm{V}=0.9$, ). Webbing moderate $(\mathrm{MTTF}=5.2, \quad \mathrm{MTFF}=6.5, \quad \mathrm{TFTF}=5.7$, FFTF=5.5). First toe (ToL I= 2.6) two times the length of the inner metatarsal tubercle (IMT= 1.3). Outer metatarsal tubercle absent, supernumerary and tarsal tubercle present on all toes.

Colouration. A morphologically variable species, with light or dark brown phase morphs where its dorsal colour varies from ashy yellow to blackish brown, with either bold or feeble dorsal patterning (Fig. 3). In life, dorsum light brown with dark brown spots; canthus rostralis dark brown, a dark brown streak from posterior of the eye through the tympanic region terminating at the shoulder; legs banded with dark brown; pupil black with gold specks around it. In preservative, dorsum grey with paired symmetrical dark markings. A pair of large spots between the occipital region followed by a broad irregular longitudinal stripe running from the temporal region to the posterior half of the body along the dorso-lateral aspect of the body. A single large spot on the flank. Limbs cream to off-white with dark grey bands. Finger in a lighter shade, toes of the same colour as the grey bands. Ventrally cream colored with heavy brown mottling on the gular region and light mottling on the limbs.

Etymology. The specific epithet refers to the type locality, Kollimalai, as a noun in apposition and hence invariable. Suggested common name: Kollimalai bush frog.

Comparison. Raorchestes kollimalai sp. nov. most closely resembles the allopatric $R$. charius of the Western Ghats, in external appearance, from which it is difficult to diagnose. However, it can be differentiated by
Table 3. Morphometric data of Raorchestes kollimalai sp. nov. holotype and paratypes (males).

\begin{tabular}{|c|c|c|c|}
\hline \multirow{4}{*}{ Character } & \multicolumn{3}{|c|}{ Raorchestes kollimalai sp. nov. } \\
\hline & Holotype & Paratype & Paratype \\
\hline & NCBS- & NCBS- & BNHS \\
\hline & BH649 & BH650 & 6068 \\
\hline SVL & 29.6 & 25.8 & 29.7 \\
\hline HW & 9.4 & 9.3 & 9.4 \\
\hline HL & 9.1 & 7.7 & 8.9 \\
\hline IUE & 4.7 & 4.3 & 4.4 \\
\hline UEW & 3.2 & 3.3 & 3.0 \\
\hline SL & 4.2 & 3.8 & 3.6 \\
\hline EL & 4.2 & 4.0 & 4.2 \\
\hline IN & 2.7 & 2.3 & 2.9 \\
\hline NS & 1.5 & 1.3 & 1.4 \\
\hline EN & 1.9 & 1.8 & 1.9 \\
\hline TYE & 0.5 & 0.6 & 0.6 \\
\hline $\mathrm{MN}$ & 7.8 & 5.3 & 6.8 \\
\hline MFE & 5.7 & 4.4 & 5.2 \\
\hline MBE & 1.7 & 1.2 & 1.1 \\
\hline IFE & 4.6 & 3.6 & 4.5 \\
\hline IBE & 8.2 & 8.3 & 7.0 \\
\hline TYD & 1.2 & 0.7 & 1.1 \\
\hline FLL & 8.2 & 6.9 & 7.8 \\
\hline HAL & 8.1 .0 & 8.0 & 8.0 \\
\hline TL & 10.3 & 11.1 & 9.8 \\
\hline ShL & 13.2 & 11.8 & 13.3 \\
\hline FOL & 11.6 & 11.1 & 11 \\
\hline TFOL & 10.9 & 10.9 & 10.7 \\
\hline TW & 2.6 & 2.3 & 2.3 \\
\hline IMT & 1.3 & 0.8 & 0.9 \\
\hline MTFF & 5.8 & 5.9 & 5.6 \\
\hline FD 1-4 & $0.8,1.2$ & $0.8,1.1$ & 0.8, 1.3, \\
\hline ГD $1-4$ & $1.5,1.4$ & $1.7,1.7$ & $1.6,1.7$ \\
\hline F I-IV L & $2.6,3.2$ & 3.0, 3.9, & 3.1, 4.0, \\
\hline Г $1-1 V \mathrm{~L}$ & $5.1,3.9$ & $5.7,3.4$ & $6.0,3.7$ \\
\hline FW 1-4 & 0.6, 0.7, & $0.5,0.7$ & $0.6,0.7$ \\
\hline FW $1-4$ & $1.0,0.9$ & $0.9,0.9$ & $0.9,0.8$ \\
\hline & $0.7,0.9$ & $0.8,0.9$ & 0.7, 0.9, \\
\hline TD 1-5 & 1.0, 1.3, & $0.9,1.3$ & 1.1, 1.2, \\
\hline & 1.4 & 1.4 & 1.3 \\
\hline & $0.6,0.5$ & $0.5,0.6$ & $0.5,0.6$ \\
\hline TW 1-5 & $0.7,0.9$ & $0.7,0.8$ & $0.7,0.8$ \\
\hline & 0.9 & 0.9 & 0.8 \\
\hline
\end{tabular}

having narrower head, HW/SVL 0.31 (vs 0.34 0.36), wider inter upper eyelid, IUE/SVL 0.140.16 (vs $0.11-0.13$ ), greater upper eyelid width, UEW/SVL $0.10-0.12$ (vs 0.06-0.09), and shorter thigh, TL/SVL $0.32-0.43$ (vs $0.44-0.51$ ); from the allopatric $R$. honnametti of Bilgiri Massif, by having larger adult male size, SVL 25.8-29.7 (vs 21.7-25.0), wider head, HL/SVL 0.31 (vs 0.33-0.40), much shorter mandible-eye distance, MBE/SVL 0.03-0.05 (vs 0.08-0.1), shorter eye-nostril distance, EN/SVL 0.0630.069 (vs 0.072-0.096), longer forelimb, 


\section{Plate 49}

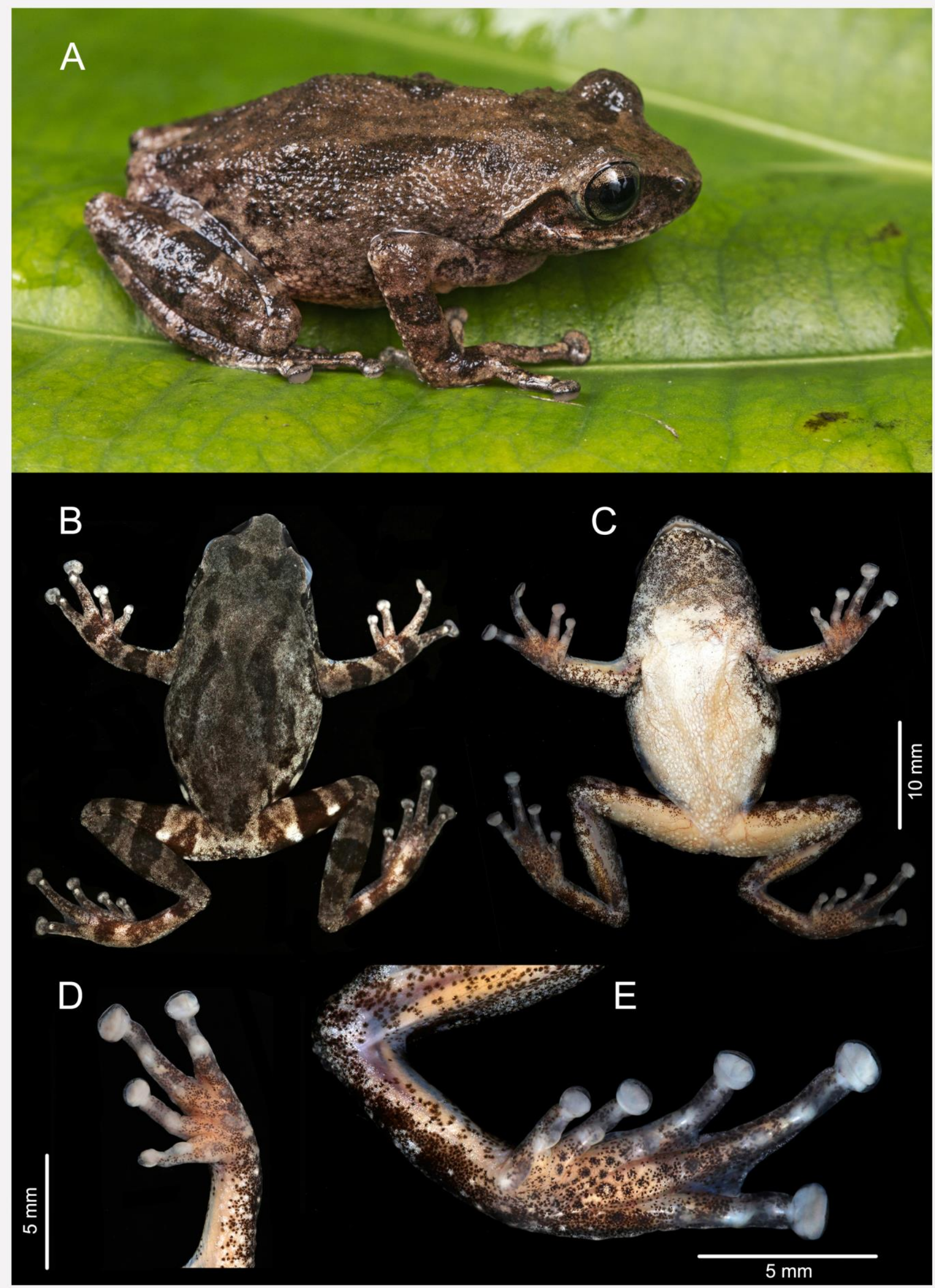

Figure 2. Adult male holotype (NCBS-BH 649) of Raorchestes kollimalai sp. nov. (A) dorsolateral view of the body in life; (B) dorsal and (C) ventral views of the body (preserved); and ventral view of the (D) right forelimb, (E) left hindlimb. 
FLL/SVL 0.26-0.27 (vs 0.20-0.24), and shorter foot, TFOL/SVL 0.36-0.42 (vs 0.44-0.74); from the allopatric $R$. griet Bossuyt, 2002 of the Southern Western Ghats, by having larger adult male body size, SVL 25.8-29.7 (vs 19.7-22.4), greater distance between upper eyelids, IUE/SVL 0.14-0.16 ( $v s$ 0.11), greater upper eyelid width, 0.10-0.12 (vs 0.05-0.09). Based on acoustic data, the new species differs from $R$. charius in its call duration, $0.305-0.34 \mathrm{~s}$ (vs $0.06-0.14 \mathrm{~s}$ ) and number of pulses per call, 2124 (vs 13-18).

Call description. Advertisement call of a single male (paratype NCBS-BH650) was recorded and ranges provided here (Fig. 4). Call syllable "treek treek treek" with varying call duration and frequency and is quite similar to that of $R$. charius. The highest frequency recorded was $22050 \mathrm{~Hz}$. Call duration was between $0.305-0.34 \mathrm{~s} \pm 0.012$; inter-call duration was $1.764-2.1 \mathrm{~s} \pm 0.128$ and number of pulse per call ranges from 21-24 \pm 1.51 (Table 4).

Table 4. Comparison of acoustic data for $R$. kollimalai sp. nov. and $R$. charius

\begin{tabular}{lcc}
\hline Feature & $\begin{array}{c}R . \\
\text { kollimalai }\end{array}$ & $\begin{array}{c}R . \\
\text { charius }\end{array}$ \\
\cline { 2 - 3 } Dominant frequency & 22050 & $2346-2541$ \\
Call duration (s) & $0.305-0.34$ & $0.06-0.14$ \\
Number of pulses & $21-24$ & $13-18$ \\
Inter-call duration (s) & $1.764-2.1$ & $1.88-3.47$ \\
\hline
\end{tabular}

Natural history. The new species is common at the type locality above $500 \mathrm{~m}$ a.s.l. It is found in sympatry with an unidentified Pseudophilautus species. Currently, the new species is known only from the type locality. However, this or similar species is likely to be found on adjacent massifs that exceed $500 \mathrm{~m}$ in elevation. The type specimens were collected from low bushes along a road in Thinnanur Nadu atop Jambuthu Slopes, in the southern part of the Kolli Hills. Calls of the species were heard from plantations, gardens, evergreen forest and mid-elevation semi-evergreen forest. The type locality is a tourist hotspot and habitat is being altered there, although patches of forest currently remain in the ghats leading to the hill top (Jayakumar et al. 2002). During surveys in 2011-12 in Kolli Hills, this species was sighted extensively and the following natural history details were gathered. Number of sightings: 173 out of $500 \mathrm{hr}$ fieldwork; encounter rate estimate: $2.8 \mathrm{hr}$ per sighting; microhabitat associations: plants $(n=100)>$ tree trunk $(n=24)>$ leaf-litter $(n=22)>$ building walls $(n=10)>$ bare ground $(n=9)>$ fallen $\log (n=4)>$ tar road $(n=2)$ and rocks $(n=2)$. Tallest perching height of a sighting was $4.2 \mathrm{~m}$ up a tree (Terminalia sp.). The new species was sighted from SengaraiNavakkadu in the north, through Kuzhi ValavuAriyur Shola regions; through SolakkaduSemmedu areas southwards to Selur NaduThinnanur Nadu (type locality). Given the current geographic range of the new species is entirely outside any Protected Area and the anthropogenic onslaught its range faces, $R$. kollimalai sp. nov. is likely a threatened species. This species is mainly nocturnal; dormant individuals were observed resting under leaf litter during day. Calling individuals were observed from as early as 18:00 $\mathrm{h}$ to up to 00:04 $\mathrm{h}$, mainly during May to September. When it rains, this species was seen calling even during broad daylight, at 12:00 noon. Heavily gravid females with apparently distended belly and developing ova faintly visible through the seethough venter, were seen during June. During late monsoon (third week of August), tiny froglets of the new species, measuring $\sim 12 \mathrm{~mm}$ in SVL (Fig. 3) were seen in dense leaf litter during the daytime.

\section{Discussion}

Raorchestes kollimalai sp. nov. shows limited diagnostic morphological characters like most cryptic species, however with geographic, molecular and acoustic data, it can be readily distinguished from other members of the clade. $R$. charius is distributed from Bababudangiri to Brahmagiri Hill range in central Western Ghats, which is at least $230 \mathrm{~km}$ a.s.l. from the type locality of $R$. kollimalai sp. nov. (Priti et al. 2016). Similarly, the intervening dry plains (< $300 \mathrm{~m}$ a.s.l.) are unsuitable for the survival of wet zone species such as bush frogs; this dry area effectively acts as a biogeographic barrier for Raorchestes. The new species currently is known only form the type locality, however, it might be found in neighboring hills of southern Eastern Ghats which share similar biotopes. Ganesh \& Arumugam (2016) reported this species (as $R$. cf. leucolatus) from Kolli Hills and Shevaroy Hills which is $\sim 40 \mathrm{~km}$ north of the type locality of $R$. kollimalai (Fig. 5). The low genetic divergence between $R$. charius and the new species is likely due to recent diversification, a scenario observed in several species of the genus Raorchestes (Vijayakumar 
et al. 2014, 2016). Such shallow divergences have been previously reported in bush frog species pairs, such as $R$. bombayensis and $R$. sanctisilvaticus (1.0\% to $1.9 \%), R$. bombayensis and $R$. tuberohumerus (1.7 to 1.9\%) (Mirza et al. 2019). The new species is phylogenetically sister to $R$. charius, despite the geographical vicinity of the type locality of the new species to that of $R$. honnametti. Sequences of the new species were included in the phylogenetic analyses by Vijayakumar et al. $(2014,2016)$, and the species was classified as being unidentified, nonetheless, distinct from $R$. charius. Although the precise locality of the samples sequenced by Vijayakumar et al. (2016) is unknown, we hypothesize that the samples originated in the Eastern Ghats. We further hypothesize that the River Cauvery acts as the biogeographic barrier for members of the clade, in addition to the intervening lowlands separating the new species and $R$. charius; however, testing this hypothesis would require investigations into the population genetics of the species of the $R$. charius clade. The Indian peninsula is flanked by two major series of mountain ranges, the Western Ghats, and the Eastern Ghats (Mani 1974). The Western Ghats are typically known for the high proportions of herpetofaunal species richness and endemism (Myers et al. 2000). The high species diversity and endemism are, primarily attributed to the elevation gradient, discontinuity due to gaps in elevation and speciation on the sky islands, and their complex geological history (Robin et al. 2010, 2017, Vijayakumar et al. 2016). As a consequence, the Western Ghats have always been at the center of attention for herpetologists, which is evident from the discovery of many new reptile and amphibian genera and species in recent years (Giri 2008, Biju et al. 2014, Mirza \& Sanap 2014, Mirza et al. 2014, Vijayakumar et al. 2014, Dinesh et al. 2015, Giri et al. 2017, Sadasivan et al. 2018, Pal et al. 2018, Vijayakumar et al. 2019). On the other hand, the Eastern Ghats have been thought of as comparatively faunally impoverished and degenerate (Mani 1974, Dinesh et al. 2009, Aengals et al. 2018, Ganesh $\&$ Arumugam 2016), with their faunal assemblage composed of derivatives from the Western Ghats (Ganesh \& Arumugam 2015). This, in turn, has resulted in comparatively fewer herpetofaunal expeditions in the Eastern Ghats. However, recent efforts to document the herpetofauna of the regions have led to the discovery of notable species of reptiles and amphibians from of the Eastern Ghats (e.g. Ganesh \& Arumugam 2016), and have also resulted in the description of new species (Aengals \& Ganesh 2013, Vogel \& Ganesh 2013, Giri et al. 2017, Mirza et al. 2017, Agarwal et al. 2019, Ganesh \& Srikanthan 2020). It is only recently that biologists have realized that, in contrast to what was previously thought, the Eastern Ghats harbor their own set of herpetofaunal assemblages, including endemics like the monotypic skink genus Sepsophis Beddome, 1870, and gecko species such as Cyrtodactylus jeyporensis (Beddome, 1878); Cnemaspis yercaudensis Das \& Bauer, 2000; C. otai Das \& Bauer, 2000; Hemidactylus kangerensis Mirza, Bhosale \& Patil, 2017; H. sushilduttai Giri, Bauer, Mohapatra et al., 2017; H. kolliensis Agarwal, Bauer, Giri et al., 2019; Hemiphyllodactylus kolliensis Agarwal, Khandekar, Giri et al., 2019, a caecilian, Gegeneophis orientalis Agarwal, Wilkinson, Mohapatra et al., 2013 (Mirza et al. 2019). Observations suggest that further species of lizards remain to be described from this region (Z.A. Mirza pers. observ.).

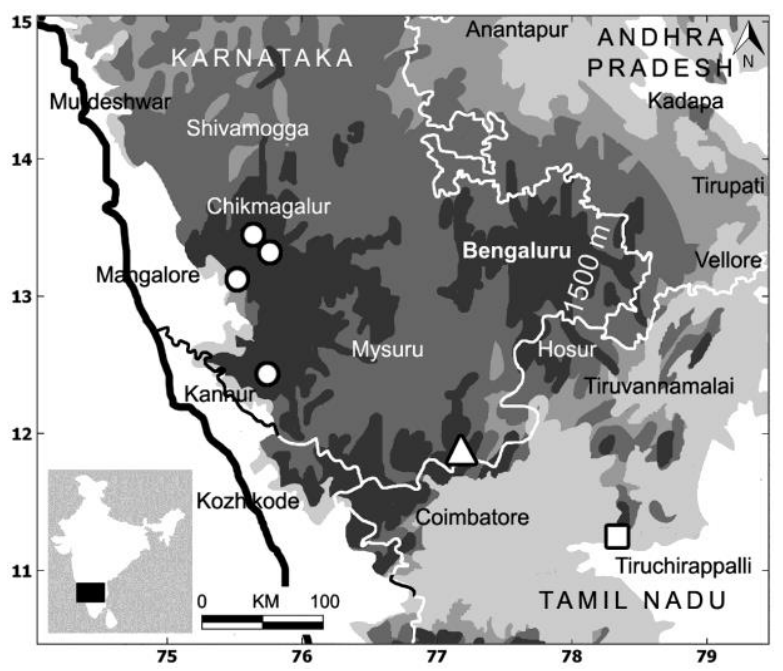

Figure 5. The distribution of the members of the Raorchestes charius clade in southern Indian peninsula; $R$. charius (circles), $R$. honnametti (triangle), and $R$. kollimalai sp. nov. (square). Map (C) A.A.T. Amarasinghe

The description of a new cryptic species of bush frogs from the Eastern Ghats adds to our growing knowledge of the genus Raorchestes and the biodiversity of the under-surveyed Eastern Ghats. The genus certainly contains several undescribed species across the Western Ghats, and perhaps also the Eastern Ghats. Evidence for multiple undescribed lineages is presented in the recent phylogeny of the genus 


\section{Plate 50}
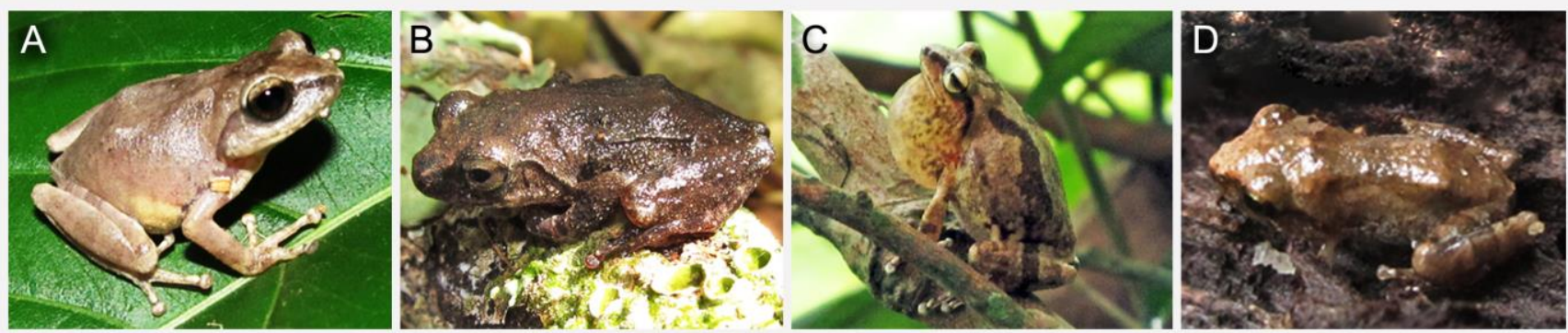

Figure 3. Raorchestes kollimalai sp. nov.; (A) pale and unpatterned body colouration, (B) dark body colouration, (C) a calling male with distended gular sac, and (D) a neonate froglet.
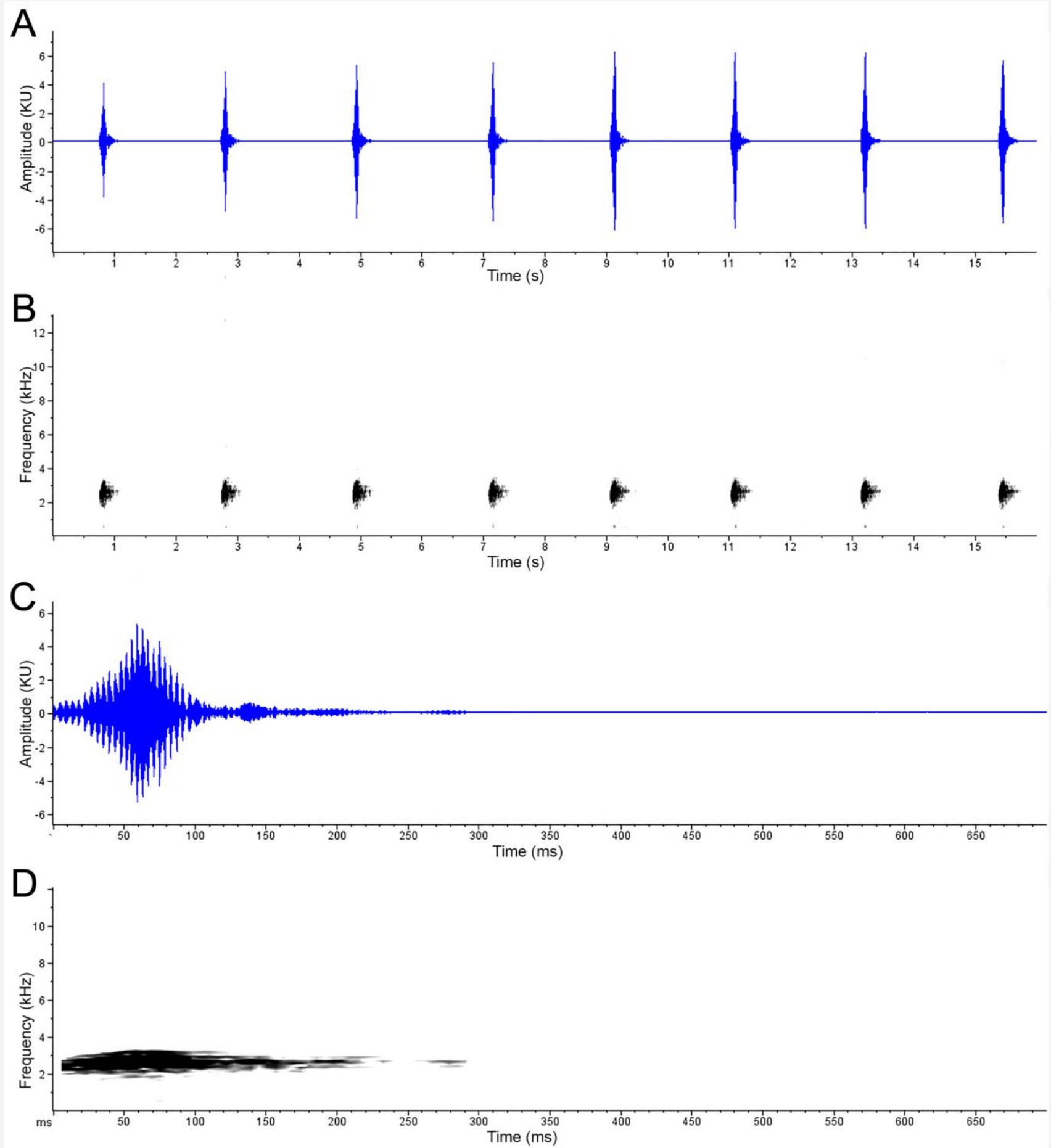

Figure 4. The advertisement call of Raorchestes kollimalai sp. nov. (A) entire call wave form, and the (B) spectrogram; (C) single call wave form, and the (D) Spectrogram 
from India (Vijayakumar et al. 2014, 2016). Morphology alone cannot be used to delimit species and additional studies incorporating molecular and acoustic data will help elucidate exact diversity of many anuran genera across India (Vijayakumar et al. 2014). A second new species of bush frog of the genus Pseudophilautus that occurs in sympatry with $R$. kollimalai sp. nov. and work in progress.

\section{Acknowledgements}

ZM thanks Singinawa Conservation Foundation and Rufford Small Grant for funding the fieldwork and the Forest Department, Tamil Nadu for permission. GG thanks A. Patwardhan (Principal), A. Kulkarni (Head, Deptartment of Biodiversity), and D. Paranjpe (advisor) at Abasaheb Garware College, Pune; and Principal and Head (Department of Biotechnology) of Fergusson College, Pune. ZM thanks K. Vijay Raghavan for hosting at NCBS, and all the lab members for the support. SRG thanks to the Chairman and Trustees of the Chennai Snake Park. We thank Pushkar Phansalkar and Atish Gawai for the support during fieldwork. Rahul Khot and Saunak Pal helped registering of types at BNHS and taking images of $R$. charius; Vivek R. helped registering of types at NCBS. Finally, Nikolay Poyarkov (Lomonosov Moscow State University, Russia) and Thasun Amarasinghe (University of Indonesia) are acknowledged for reviewing the manuscript.

\section{Literature cited}

Agarwal, I., A. Khandekar, V. Giri, U. Ramakrishnan, and P. Karanth (2019). The hills are alive with geckos! A radiation of a dozen species on sky islands across peninsular India (Squamata: Gekkonidae, Hemiphyllo dactylus) with the description of three new species. Organisms Diversity \& Evolution, 19: 341-361.

Aengals, R. and S.R. Ganesh (2013). Rhinophis goweri-a new species of shieldtail snake from the southern Eastern Ghats, India. Russian Journal Herpetology, 20 (1): 61-65.

Aengals, R., V.S. Kumar, M.J. Palot, and S.R. Ganesh (2018). Checklist of reptiles of India <www.zsi.gov.in/checklist/reptiles> ZSI epublication. Zoological Survey of India: 36pp.

Biju, S.D. and F. Bossuyt (2009). Systematics and phylogeny of Philautus Gistel, 1848 (Anura, Rhachophoridae) in the Western Ghats of India, with description of 12 new species. Zoological Journal of Linnean Society, 155: 374-444.
Biju, S.D., Y. Shouche, A. Dubois, S.K. Dutta, and F. Bossuyt (2010). A ground-dwelling rhachophorid frog from the highest mountain peak of the Western Ghats of India. Current Science, 98 (8): 1119-1125.

Biju, S.D., S. Garg, K.V. Gururaja, Y. Shouche, and S.A. Walujkar (2014). DNA barcoding reveals unprecedented diversity in dancing frogs of India (Micrixalidae, Micrixalus): a taxonomic revision with description of 14 new species. Ceylon Journal of Science (Biological Sciences), 43 (1): 37-123.

Bossuyt, F. and A. Dubois (2001). A review of frog genus Philautus Gistel, 1848 (Amphibia, Anura, Ranidae, Rhachophorinae). Zeylanica, $6(1): 1-112$.

Dinesh, K.P., S.P. Vijayakumar, B.H.C. Murthy, V. Toreskar, N. Kulkarni et al. (2015). Systematic status of Fejervarya (Amphibia, Anura, Dicroglossidae) from South and SE Asia with the description of a new species from the Western Ghats of Peninsular India. Zootaxa, 3999 (1): 79-94.

Ganesh, S.R. and M. Arumugam (2015). Microhabitat use and abundance estimates of under storey herpetofauna in the highlands of southern Eastern Ghats, India, with observations on roadkill mortalities. Asian Journal of Conservation Biology, 4 (2): 143150.

Ganesh, S.R., and M. Arumugam (2016). Species richness of montane herpetofauna of southern Eastern Ghats, India: a historical resume and a descriptive checklist. Russian Journal of Herpetology, 23: 7-4.

Ganesh, S.R. and A.N. Srikanthan (2020). A new species of shieldtail snake (Reptilia: Squamata: Uropeltidae) from Kolli Hill complex, southern Eastern Ghats, peninsular India. Journal of Threatened Taxa, 12 (4): 15436-15442.

Giri, V.B. (2008). A new rock-dwelling Hemidactylus (Squamata: Gekkonidae) from Maharasshtra, India. Hamadryad, 34: 25-33.

Giri, V.B., A.M. Bauer, P. Mohapatra, C. Srinivasulu, and I. Agarwal (2017). A new species of large-bodied, tuberculate Hemidactylus Oken (Squamata: Gekkonidae) from the Eastern Ghats, India. Zootaxa, 4347 (2): 331-345.

Gururaja, K.V., K.P. Dinesh, H. Priti, and G. Ravikanth (2014). Mud-packing frog: a novel breeding behaviour and parental care in a stream dwelling new species of Nyctibatrachus (Amphibia, Anura, Nyctibatrachidae). Zootaxa, 3796 (1): 33-61. 
Jayakumar, S, D.I. Arockiasamy, and S.J. Britto (2002). Conserving forests in the Eastern Ghats through remote sensing and GIS-A case study in Kolli Hills. Current Science, 82 (10): 1259-1266.

Kalyaanamoorthy, S., B. Minh, T. Wong, A. von Haeseler, and L. Jermiin (2017). ModelFinder: fast model selection for accurate phylogenetic estimates. Nature Methods, 14: 587-589.

Kumar, S., G. Stecher, M. Li, C. Knyaz, and K. Tamura (2018). MEGA X: Molecular Evolutionary Genetics Analysis across computing platforms. Molecular Biology \& Evolution, 35: 1547-1549.

Lanfear, R., B. Calcott, S. Ho, and S. Guindon (2012). PartitionFinder: combined selection of partitioning schemes and substitution models for phylogenetic analyses. Molecular Biology \& Evolution, 29: 1695-1701.

Mani, M. (ed.) (1974). Ecology and biogeography in India. Springer Science and Business Media. Volume 23: 773pp.

Mirza, Z.A and R.V. Sanap (2014). A new cryptic species of gecko of the genus Hemidactylus Oken, 1817 (Reptilia: Gekkonidae) from Southern India. Taprobanica, 6: 12-20.

Mirza, Z.A., S. Pal, H. Bhosale, and R. Sanap (2014). A new species of gecko of the genus Cnemaspis Strauch, 1887 from the Western Ghats, India. Zootaxa, 3815: 494-506.

Mirza, Z.A., H. Bhosale, and R. Patil (2017). A new large species of gecko of the genus Hemidactylus Oken, 1817 (Reptilia: Sauria: Gekkonidae) from the Eastern Ghats, India. Comptes Rendus Biologies, 340: 531-540.

Mirza, Z.A., P. Warekar, P. Mohapatra, D. Raju, P. Patil et al. (2019). Endangered or an artifact of unsound taxonomy: case of the critically endangered bush frog Philautus sanctisilvaticus Das and Chanda, 1997. Zootaxa, 4683 (4): 563-576.

Myers, N., R.A. Mittermeier, C.G. Mittermeier, G.A. da Fonseca, and J. Kent (2000). Biodiversity hotspots for conservation priorities. Nature, 403: 853-858.

Nguyen, L., H. Schmidt, A. von Haeseler, and B. Minh (2015). IQ-TREE: A fast stochastic algorithm for estimating maximum likelihood phylogenies. Molecular Biology \& Evolution, 32: 268-274.

Pal, S., S.P. Vijayakumar, K. Shanker, A. Jayarajan, and V. Deepak (2018). A systematic revision of Calotes Cuvier, 1817 (Squamata: Agamidae) from the Western Ghats adds two genera and reveals two new species. Zootaxa, 4482 (3): 401-450.
Priti, H., R. Roshmi, B. Ramya, H. Sudhira, G. Ravikanth et al. (2016). Integrative Taxonomic approach for describing a new cryptic species of bush frog (Raorchestes: Anura: Rhacophoridae) from the Western Ghats, India. PLoS ONE, 11: e0149382.

Robin, V. V., A. Sinha, and U. Ramakrishnan (2010). Ancient geographical gaps and paleoclimate shape the phylogeography of an endemic bird in the sky islands of southern India. PLOS ONE, 5: e13321.

Robin, V.V., C.K. Vishnudas, P. Gupta, F.E. Rheindt, D.M. Hooper et al. (2017). Two new genera of songbirds represent endemic radiations from the Shola Sky Islands of the Western Ghats, India. BMC Evolutionary Biology, 17: 31.

Ronquist, F. and J. Huelsenbeck (2003). MrBayes 3: Bayesian phylogenetic inference under mixed models. Bioinformatics, 19: 15721574.

Sadasivan, K., M.B. Ramesh, M.J. Palot, M. Ambekar, and Z. A. Mirza (2018). A new species of fan-throated lizard of the genus Sitana Cuvier, 1829 from coastal Kerala, southern India. Zootaxa, 4374: 545-564.

Thompson, J., T. Gibson, and D.G. Higgins (2003). Multiple sequence alignment using ClustalW and ClustalX. In: Current protocols in Bioinformatics, Chapter 2, Unit 2.3.

Trifinopoulus, J., L. Nguyen, A. von Haeseler, and B. Minh (2016). W-IQ-TREE: a fast online phylogenetic tool for maximum likelihood analysis. Nucleic Acid Research, 22 (22): 4673-4680.

Vijayakumar, S.P., K.P. Dinesh, M.V. Prabhu, and K. Shanker (2014). Lineage delimitation and description of nine new species of bush frogs (Anura: Raorchestes, Rhacophoridae) from the Western Ghats Escarpment. Zootaxa, 3893: 451-488.

Vijayakumar, S.P., R.C. Menezes, A. Jayarajan, and K. Shanker (2016). Glaciations, gradients, and geography: Multiple drivers of diversification of bush frogs in the western ghats escarpment. Proceedings of the Royal Society B: Biological Sciences 283: 20161011.

Vogel, G., and S.R. Ganesh (2013). A new species of cat snake (Reptilia: Serpentes: Colubridae: Boiga) from dry forests of eastern Peninsular India. Zootaxa, 3637: 158-168.

Yu, G., D. Rao, M. Zhang, and J. Yang (2009). Re-examination of the phylogeny of Rhachophoridae (Anura) based on mitochondrial and nuclear DNA. Molecular Phylogenetics \& Evolution, 50: 571-579.

Published date: 28 November 2020 